\title{
Saint-Evremond au miroir du temps. Actes du colloque du trecentenaire de sa mort, Caen-Saint-Lô (9-11 octobre 2003), édités par Suzanne Guellouz
}

\section{Monica Pavesio}

\section{(2) OpenEdition}

\section{Journals}

\section{Edizione digitale}

URL: http://journals.openedition.org/studifrancesi/9197

DOI: 10.4000/studifrancesi.9197

ISSN: 2421-5856

\section{Editore}

Rosenberg \& Sellier

\section{Edizione cartacea}

Data di pubblicazione: 1 juin 2008

Paginazione: 181

ISSN: 0039-2944

\section{Notizia bibliografica digitale}

Monica Pavesio, «Saint-Evremond au miroir du temps. Actes du colloque du trecentenaire de sa mort, Caen-Saint-Lô (9-11 octobre 2003), édités par Suzanne Guellouz», Studi Francesi [Online], 154 (LII | I) | 2008, online dal 30 novembre 2015, consultato il 11 janvier 2021. URL: http://

journals.openedition.org/studifrancesi/9197 ; DOl: https://doi.org/10.4000/studifrancesi.9197

Questo documento è stato generato automaticamente il 11 janvier 2021.

\section{cc) (†) $\odot$}

Studi Francesi è distribuita con Licenza Creative Commons Attribuzione - Non commerciale - Non opere derivate 4.0 Internazionale. 
Saint-Evremond au miroir du temps. Actes du colloque du trecentenaire de sa mort, Caen-Saint-Lô (9-11 octobre 2003), édités par Suzanne Guellouz

\author{
Monica Pavesio
}

\title{
NOTIZIA
}

Saint-Evremond au miroir du temps. Actes du colloque du trecentenaire de sa mort, CaenSaint-Lô (9-11 octobre 2003), édités par Suzanne GUELLouz, (Biblio17-157), Tübingen, Gunter Narr Verlag, 2005, pp. 319.

1 Il volume raccoglie gli atti del convegno dedicato a Saint-Evremont in occasione del trecentenario della sua morte, tenutosi nel 2003 presso l'Università di Caen e gli archivi dipartimentali di Saint-Lô.

2 Come spiega la curatrice nella prefazione, si è lasciato spazio in apertura del volume alla trascrizione ed al commento di una lettera scritta dal letterato all'abate Hautefeuille, scoperta nella Biblioteca municipale di Caen nel 2002 e non inserita da Denys Potts nel suo volume Saint-Evremond: A Voice from Exile, perché già in stampa al momento della scoperta.

Le comunicazioni contenute nel volume sono suddivise in quattro sezioni.

4 La prima è consacrata a Saint-Evremond uomo di teatro: L. CAMINITI-PENNAROLA analizza i testi teorici scritti in Olanda fra il 1666 ed il 1667 (Saint-Evremond et le genre de la comédie, pp. 23-48); J.M. CIVARDI si occupa della pièce La Comédie des Académistes (pp. 49-74); Ch. BIET di Sir Politick Would-Be (pp. 75-98); J. LE BLANC di Les Opera (pp. 99-118). 
5 La seconda sezione è dedicata al critico letterario, con un intervento di M.G. LALLEMAND sul rapporto fra Saint-Evremond ed il romanzo (pp. 121-136), un interessante saggio di E. BURY sulla posizione tenuta da Saint-Evremond nella famosa Querelle des Anciens et des Modernes (pp. 137-148); una comunicazione di S. GUellouz sul ruolo che la Spagna ha giocato nella vita e nella scrittura del critico (pp. 149-166).

6 La terza sezione si occupa di Saint-Evremond moralista e filosofo. R. HODGSON avvicina e confronta Saint-Evremond con La Rochefoucauld (pp. 169-184); D. RIOU analizza lo scetticismo del filosofo (pp. 185-202); A. NIDERST indaga i suoi rapporti con i libertini (pp. 203-214); P. HOURCADE studia la scrittura della storia (pp. 215-230); M. JASPERS la coscienza storica (pp. 231-246).

7 La quarta ed ultima sezione indaga la posterità immediata e lontana di Saint-Evremond: F. WILD analizza la prima ricezione delle opere del letterato fra il 1670 ed il 1706 (pp. 249-276); J. DAGEN studia i rapporti fra Marivaux e Saint-Evremond (pp. 277-292); J. GOLDZINK confronta il filosofo con Voltaire (pp. 293-298); l'ultimo saggio di G. POULOUIN repertoria ed analizza i numerosi testi dedicati al critico, al filosofo ed allo scrittore nel corso del xx secolo (pp. 299-319). 